\title{
IMAGE OF THE MONTH
}

\section{Anorectal melanoma: An uncommon and aggressive disease}

\author{
Maria João Magalhães MD, Marta Salgado MD, Isabel Pedroto MD
}

\section{CASE PRESENTATION}

A 74-year-old woman was admitted to hospital in August 2010 for community-acquired pneumonia. Laboratory investigations revealed iron deficiency anemia (hemoglobin $104 \mathrm{~g} / \mathrm{L}$ ) and a thoracic computed tomography scan revealed scattered bilateral nodular opacities compatible with pulmonary metastasis of unknown primary site. In the diagnostic workup, the colonoscopy revealed a $40 \mathrm{~mm}$ vegetating lesion with a brownish surface at the distal rectum involving the anorectal transition (Figures 1 and 2). Histological analysis revealed an ulcerated malignancy with pleomorphic epithelioid cells and abundant melanophages (Figures 3 and 4). Immunohistochemical staining was positive for S-100, HMB-45 and Melan-A proteins, establishing the diagnosis of anorectal melanoma. She also had brain metastases. Due to the global status, symptomatic treatment was proposed. The patient died six months later.

\section{DISCUSSION}

Primary anorectal melanoma is a rare and aggressive disease, representing $<1 \%$ of all melanomas, and approximately $0.5 \%$ to $2 \%$ of all anorectal malignancies (1). It is slightly more predominant in females, primarily in the fifth and sixth decades of life (1). The tumour can arise directly from melanocytes located above the dentate line, where there are abundant lymphatics and blood vessels that enable the tumour to grow and metastize quickly (2). It usually presents with symptoms such as rectal bleeding, anorectal pain, rectal mass or change in bowel habits (1). It has a very poor prognosis. The mean survival after diagnosis is 15 to 25 months. At diagnosis, $>20 \%$ have distant metastases (3).

The optimal treatment is controversial. Surgical resection is the conventional therapy and includes abdominoperineal resection and wide local excision with or without adjuvant therapy $(1,3)$.

DISCLOSURES: The authors have no financial disclosures or conflicts of interest to declare.

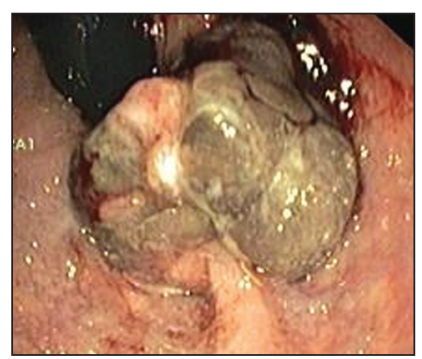

Figure 1) Tumour with brownish surface at the distal rectum

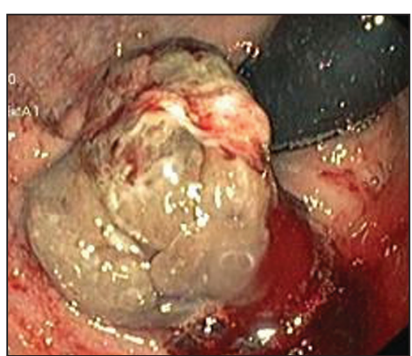

Figure 2) Endoscopic view showing easy bleeding

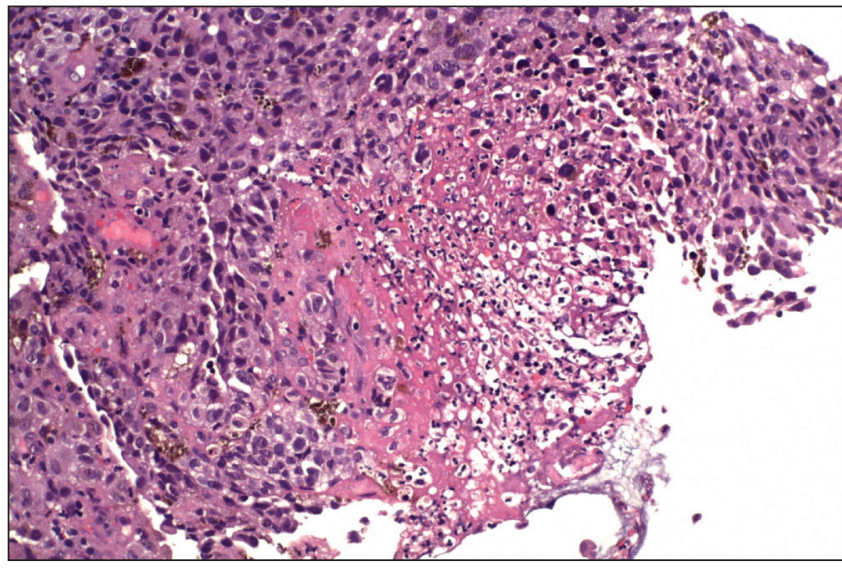

Figure 3) Poorly differentiated cell population with necrosis and ulceration (hematoxylin and eosin stain, original magnification $\times 200$ )

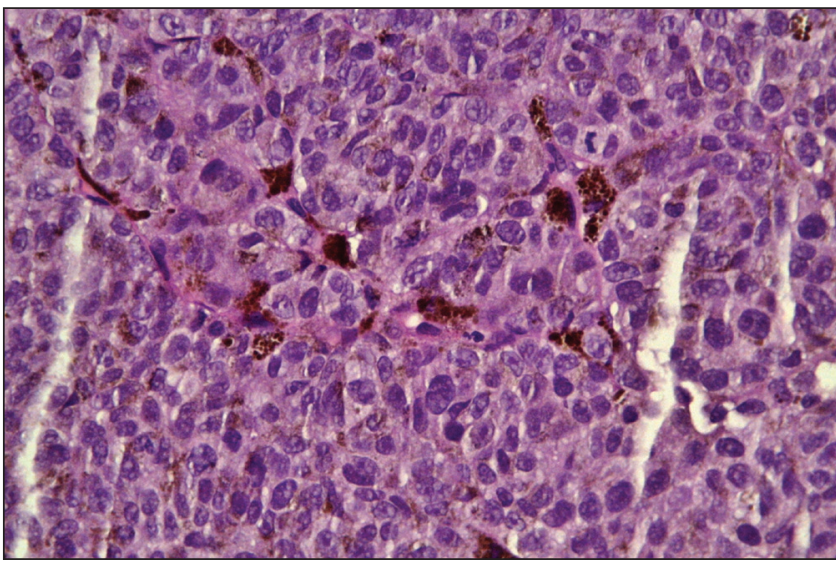

Figure 4) Detail of poorly differentiated cell population with melanophages and mitosis (hematoxylin and eosin stain, original magnification $\times 400$ )

\section{REFERENCES}

1. Khan M, Bucher N, Elhassan A, et al. Primary anorectal melanoma. Case Rep Oncology 2014;7:164-70.

2. Carcoforo P, Raiji MT, Palini GM, et al. Primary anorectal melanoma: An update. J Cancer 2012;3:449-53.

3. Heyman BM, Chung MM, Lark AL, Shofer S. Endobronchial metastasis from primary anorectal melanoma. Am J Case Rep $2013 ; 14: 253-7$

\begin{abstract}
The Canadian Journal of Gastroenterology $\mathcal{E}$ Hepatology is considering a limited number of submissions for IMAGE OF THE MONTH. These are based on endoscopic, histological, radiological and/or patient images, which must be anonymous with no identifying features visible. The patient must consent to publication and the consent must be submitted with the manuscript. All manuscripts should be practical and relevant to clinical practice, and not simply a case report of an esoteric condition. The text should be brief, structured as CASE PRESENTATION and DISCUSSION, and not more than 700 words in length. A maximum of three images can be submitted and the number of references should not exceed five. The submission may be edited by our editorial team.
\end{abstract}

Department of Gastroenterology, Centro Hospitalar do Porto - Hospital de Santo António, Porto, Portugal

Correspondence: Dr Maria João Magalhães, Rua Dr Manuel Rodrigues de Sousa, $215^{\circ}$ D, 4450-181 Matosinhos, Porto, Portugal.

Telephone 351-93-312-8979, e-mailmj.magalhaes@gmail.com

Received for publication August 1, 2014. Accepted August 4, 2014 


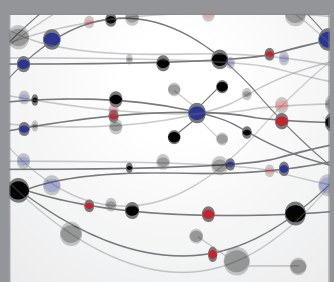

The Scientific World Journal
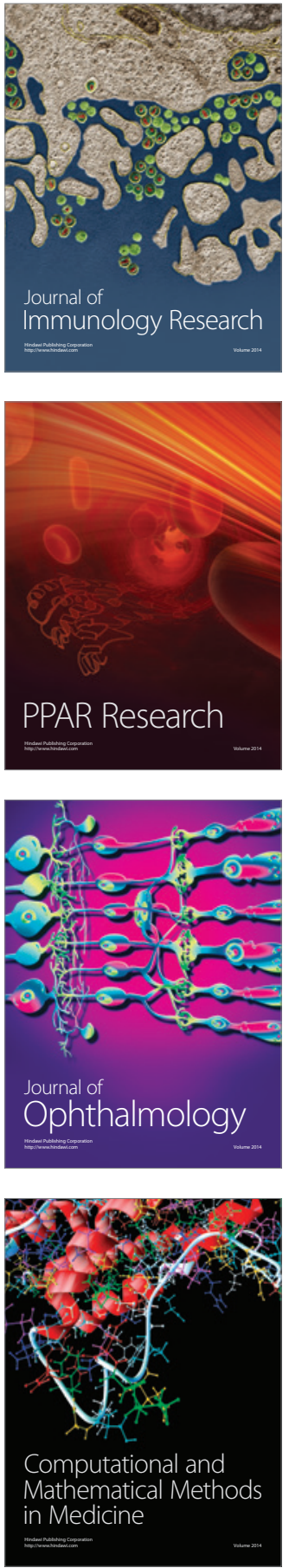

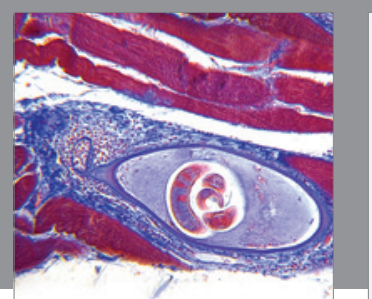

Gastroenterology Research and Practice

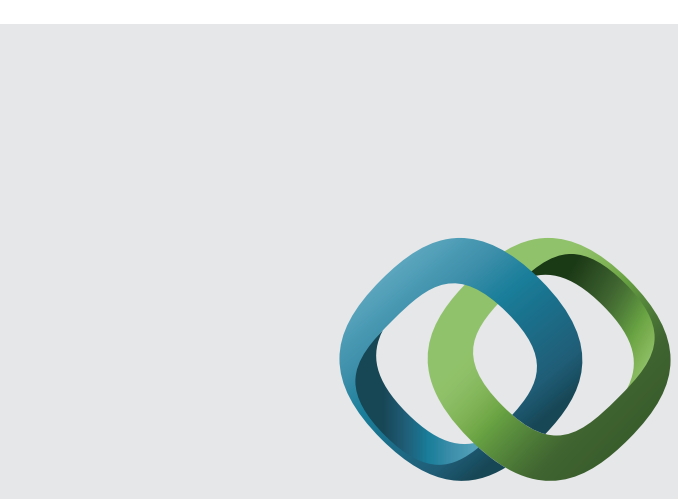

\section{Hindawi}

Submit your manuscripts at

http://www.hindawi.com
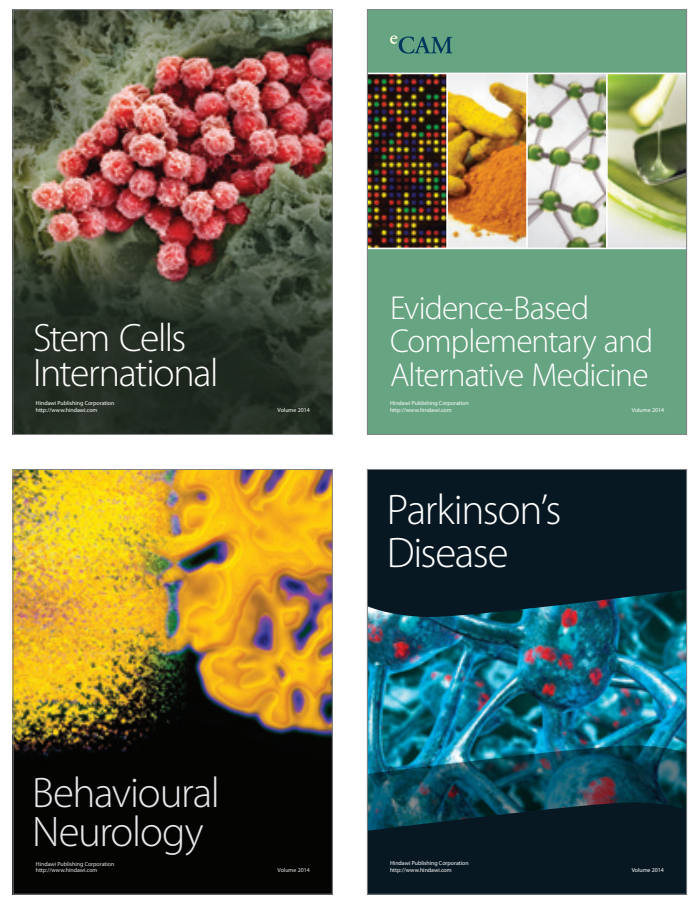
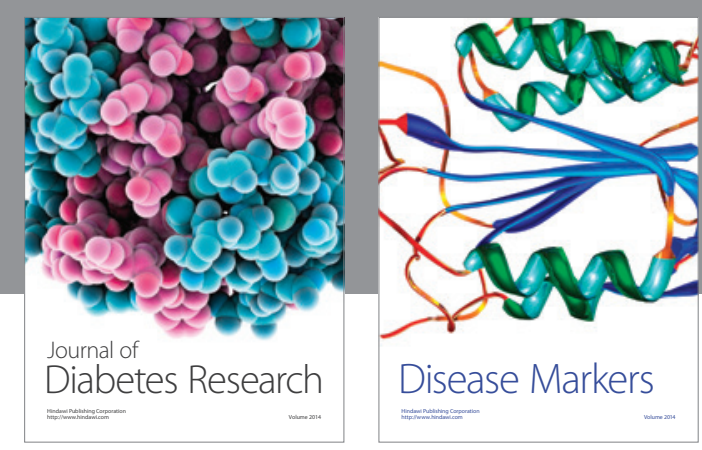

Disease Markers
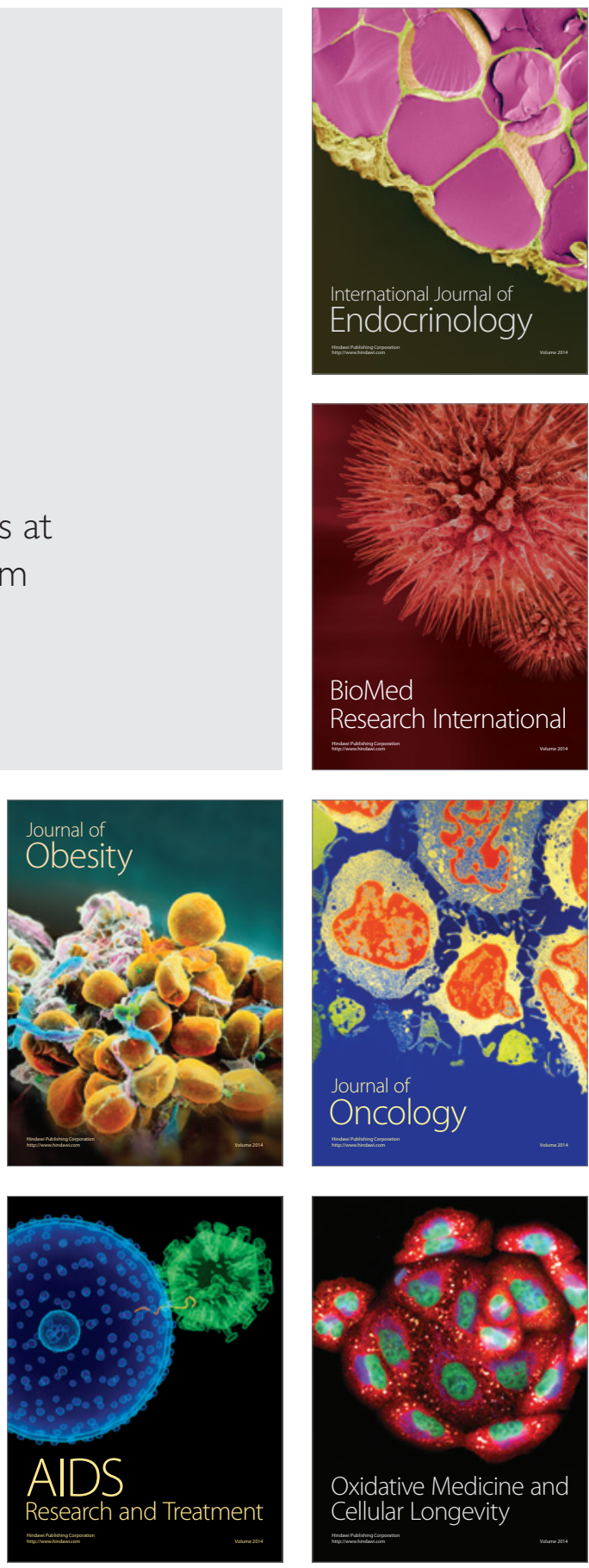